Voix et Images

voixetimages

\title{
Le Film des Jeux olympiques
}

\section{Gilles Thérien}

Volume 3, numéro 1, septembre 1977

Nicole Brossard

URI : https://id.erudit.org/iderudit/200098ar

DOI : https://doi.org/10.7202/200098ar

Aller au sommaire du numéro

\section{Éditeur(s)}

Les Presses de l'Université du Québec

\section{ISSN}

0318-9201 (imprimé)

1705-933X (numérique)

Découvrir la revue

\section{Citer cet article}

Thérien, G. (1977). Le Film des Jeux olympiques. Voix et Images, 3(1), 157-158.

https://doi.org/10.7202/200098ar d'utilisation que vous pouvez consulter en ligne.

https://apropos.erudit.org/fr/usagers/politique-dutilisation/ 


\section{Le Film des Jeux olympiques}

Le battage publicitaire est grand. C'est un excellent film. Les techniciens, les cinéastes impliqués dans cette aventure n'ont plus rien à prouver. L'ONF, dans ce genre de cinéma, est à la hauteur de la situation. Dans ces deux heures, j'y ai vu plusieurs choses attachantes. J'ai vu des images soignées, uniques par rapport à ce que la télévision nous a offert.

Et puis, après, je me suis demandé ce que tout cela faisait là... Et j'ai commencé à penser à ce que je n'avais pas vu. Je n'ai pas vu le stade incomplet, que je vais payer pendant plusieurs années. Je n'ai pas vu l'imbroglio de Taïwan avec les athlètes refoulés à la frontière, les chevaux parqués en quarantaine. Une petite image ou deux sur la défection des pays d'Afrique. Je n'ai vu ni l'appareil policier ni l'appareil militaire qui ont assuré la sécurité des Jeux, c'est-à-dire qui ont été le souvenir vivant, cruel, des Jeux de Munich. Je n'ai pas vu les protestataires roumains ou soviétiques qui réclamaient la liberté des gens de leurs pays. Je n'ai pas vu la délégation d'Israël ni celle des pays arabes. Je n'ai pas vu les spectateurs suffisamment riches pour se payer des places. Je n'ai pas vu ceux qui s'adonnaient à la revente illégale des billets à des prix fabuleux. Je n'ai pas vu les athlètes qui se cherchaient des femmes ou le contraire. Je n'ai pas vu ceux que leur condition financière écartait des Jeux et qui devaient se contenter de leur petite boîte à images. J'ai à peine vu la Reine, je l'ai entendue, mais je n'ai pas vu le menaçant Lord Killanin ni l'ineffable Française dont j'ai oublié le nom (heureusement!) qui se permettait les déclarations les plus gentilles à notre endroit.

Le film sur les Jeux a réussi, et c'est un tour de force, à escamoter toutes les choses importantes qui se sont passées aux Jeux, y compris la remise en question de l'amateurisme, de l'utilité de cette grande foire qui consacre des héros qui n'ont d'existence qu'au moment où un système électronique enregistre des records. Le film a appuyé la thèse de l'héroïsme, de la candide opposition entre l'extraordinaire athlète ( - qui sur le plan humain n'est peut-être qu'une vadrouille) et le pauvre vaincu, dont le drame est loin d'être abyssal. Ce film perpétue le système qu'il regarde, n'opère aucune distance entre son objet et son regard, ne tient aucunement compte des coulisses, des intérêts cachés et pourtant omniprésents qui font de ce genre de spectacle une dérisoire illustration du «panem et circenses".

Évidemment, on objectera que ce film n'a pas voulu être autre chose qu'un regard humain sur des événements humains. II faudra alors noter que l'humain est en train de se simplifier dangeureusement. La moralité au cinéma n'est pas une vertu, elle est une façon de voir. Or ce film 
réussit à être aussi immoral, aussi hypocrite que le Comité international olympique et que tous ceux qui grenouillent à un niveau ou à un autre de cette mare nauséabonde.

Les Jeux olympiques sont devenus un scandale, économique, politique, esthétique. Leur mise en place, du moins, à Montréal, est une blessure dont on ne guérira pas facilement. Cette immense broyeuse a été gommée du film. Ça n'existe pas. L'événement s'est limité à son aboutissement programmé; la programmation s'est mystérieusement absentée. L'ONF qui a, depuis des années, développé un regard critique sur le plan social dans sa production cinématographique, a lamentablement failli à la tâche au moment précis où cette force de l'ONF pouvait permettre, pour la première fois, autre chose qu'un film de propagande.

La couverture électronique ou écrite au jour le jour des Jeux a permis de nous faire sentir que tout n'était pas que foulée sur la piste du stade... mais l'instantanéité de la nouvelle entraîne la rapidité de son effacement. II appartenait au film-témoin d'être un témoin, de réinsérer dans son regard la dimension complexe de l'événement, de ne pas craindre de dénoncer les souliers de course de Lace Viren, les faux Amérindiens roses et verts, le choix et le retrait des athlètes, la mesquinerie des athlètes américains envers ceux des pays de l'Est, l'utilisation de la drogue (ex. les anabolisants) et les difficultés du contrôle anti-doping, la tricherie d'un escrimeur soviétique qu'on retrouve euphémisée par un commentaire, la victoire de Walker en l'absence de Bailly. On évite même de montrer l'haltérophile bulgare, disqualifié après les Jeux. Bien sûr, si on avait montré tout cela, on aurait fait un film gênant. Or il s'agissait du film «officiel". Et quand on tombe dans l'officiel...

J'espère seulement qu'un amateur honnête a su promener sa caméra super-huit sur ces événements et qu'il l'a fait spontanément sans les dénaturer avec leurs splendeurs mais aussi leurs ténèbres. Si ce film existe, c'est sans doute le vrai film des Jeux olympiques de Montréal, celui que l'on ne verra jamais parce qu'il faut à tout prix conserver dans le monde entier la plus béate des illusions.

Gilles Thérien 